\title{
A Importância do Marketing de Relacionamento na Gestão das Instituições de Ensino Superior Privadas \\ The Importance of the Relationship's Marketing in Management of Private Institutions in Superior Education
}

\author{
Débora Cristina Lopes Martins ${ }^{1}$ \\ Ivanete da Rosa Silva de Oliveira ${ }^{2}$ \\ Sandro José Martins ${ }^{3}$
}

\section{Resumo}

O artigo apresentado enfoca a relevância do marketing de relacionamento como um dos principais diferenciais para a sobrevivência das instituições de ensino superior privadas. No cenário atual, em que a concorrência acirrada, guerra de preços e ausência de barreiras a novos entrantes constituem grandes ameaças e diminuem a competitividade das instituições, somente a adoção de estratégias de relacionamento, aliadas às Tecnologias de Informática, serão capazes de garantir a sobrevivência no mercado institucional.

Palavras-chave: Marketing; Relacionamento; Instituição de Ensino.

\section{Abstract}

The presented article focuses the relevance of the relationship marketing as one of the main differentials for the survival of the private institutions of superior education. In the current scene, where the incited competition, war of prices and absence of barriers new the incoming ones constitute great threats and diminish the competitiveness of the institutions, only the adoption of strategies of relationship, allied to the technologies of the Information, will be capable to guarantee the survival in the institutional market.

Key-words: Marketing, Relationship, Institution of Education.

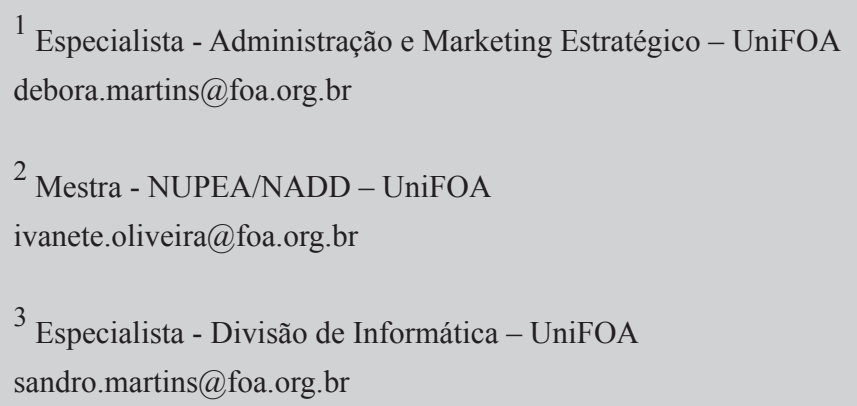




\section{Introdução}

O marketing é um termo relativamente novo no ambiente acadêmico e passou a ser uma questão de estratégia de sobrevivência para as Instituições de Ensino Superior Privadas (IESP), pois a concorrência no ambiente educacional passou a ser significativa.

$\mathrm{O}$ mercado educacional, que compreende a adição de todas as pessoas que estudam, estudaram ou podem vir a estudar numa Instituição de Ensino Superior Privada, está cada vez mais competitivo. E nesse cenário de mais competição e clientes cada vez mais exigentes, a adoção de estratégias de marketing que permitam a obtenção de vantagem competitiva sustentável para as IESP torna-se fator de garantia da sobrevivência.

Depois de vários anos crescendo a taxas superiores a $15 \%$ ao ano, pela primeira vez, de 2003 para 2004, o número de matrículas em instituições privadas cresceu a uma taxa abaixo de 10\% (o crescimento foi de $8,5 \%$ ). O número de alunos por curso tem caído ano após ano, chegando ao seu nível mais baixo em 2004. (GARCIA, 2006, p. 16).

A realidade desse cenário pode ser comprovada pelos dados dos gráficos abaixo, em que verificamos que o crescimento do número de instituições de ensino superior privadas e a oferta de novos cursos são superiores ao número de ingressantes oriundos do ensino médio.

No ano de 1999, existiam, no Brasil, 905 instituições de ensino superior privadas. Em 2004, foram registradas 1.789 IESP, ou seja, a oferta educacional cresceu 97\% em apenas cinco anos.



Gráfico 1 - Evolução do número de instituições de ensino superior privadas, no Brasil

Fonte: www.edudatabrasil.inep.gov.br
No ano de 1999, as instituições de ensino superior privadas ofertavam 5.384 cursos. Em cinco anos, a oferta de cursos cresceu $129,5 \%$, como se podemos observar no gráfico 2 .

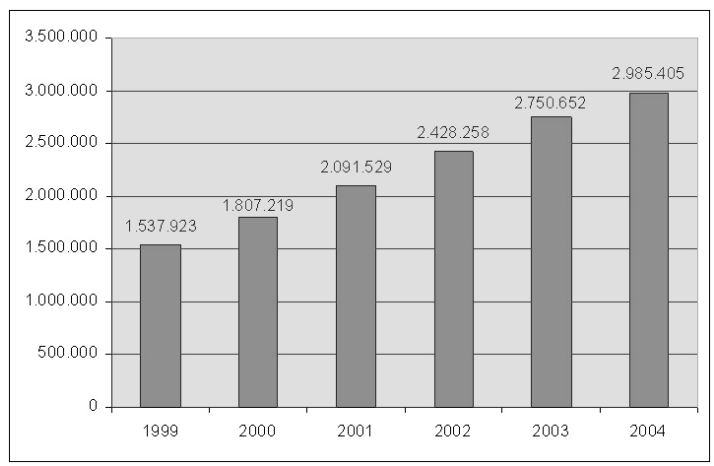

Gráfico 2 - Evolução do número de cursos oferecidos por IESP, no Brasil.

Fonte: www.edudatabrasil.inep.gov.br

No ano de 1999, havia 1.537.923 alunos matriculados em instituições de ensino superior privadas no Brasil. Em 2004, esse número era de 2.985.405 alunos matriculados, representando um crescimento de $94 \%$ ao final de cinco anos. Esse cenário confirma que o número de alunos matriculados ao longo de cinco anos cresceu em proporção inferior (94\%) ao número de cursos ofertados (129,5\%).

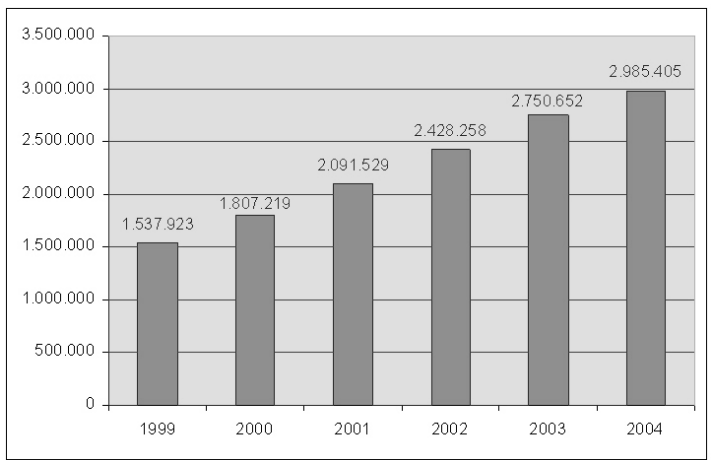

Gráfico 3 - Evolução do número de alunos matriculados em instituições de ensino superior privadas, no Brasil. Fonte: www.edudatabrasil.inep.gov.br

Ao considerarmos o número de alunos matriculados por IESP no Brasil, o cenário torna-se ainda mais crítico, pois percebemos que, em cinco anos, não houve crescimento no número de alunos matriculados por instituição, mas uma queda de 1,76\%. 


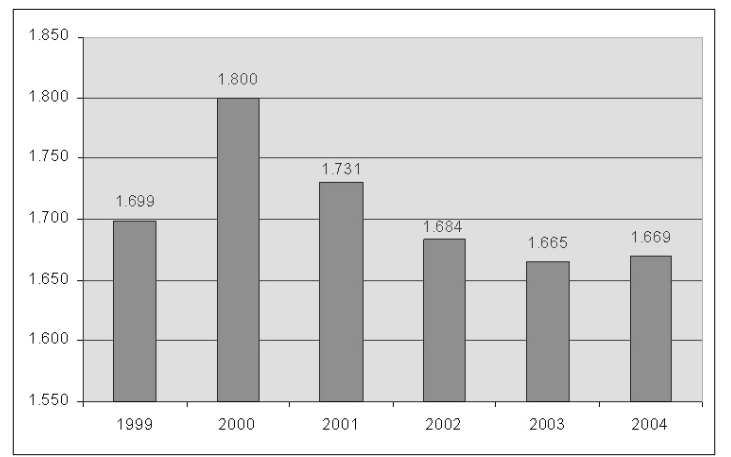

Gráfico 4 - Evolução do número de alunos matriculados por IESP. Fonte: www.edudatabrasil.inep.gov.br

A evolução do número de alunos matriculados por curso em instituições de ensino superior privadas, apresentou uma queda de $15,7 \%$ nos últimos cinco anos. Em contrapartida ao aumento do número de IESP, tivemos uma queda no número de ingressantes por curso.

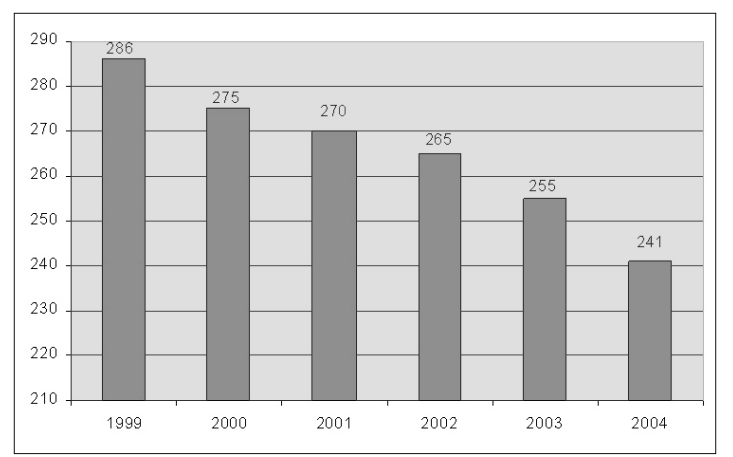

Gráfico 5 - Evolução do número de alunos matriculados por curso em instituições de ensino superior privadas, no Brasil. Fonte: www.edudatabrasil.inep.gov.br

Com a expansão da oferta educacional e conseqüente diluição da demanda, as Instituições de Ensino Superior Privadas vêm modificando suas estratégias para captação de alunos e percebendo cada vez mais a necessidade imperativa da utilização do marketing educacional e, mais precisamente, do marketing de relacionamento para manter seus alunos e diferenciar-se da concorrência.

Portanto, nesse cenário competitivo, em que a crescente oferta de novos cursos de graduação, novos entrantes no setor educacional, ausência de barreiras para abertura de novos cursos, concorrência desleal focada no preço em detrimento da qualidade de ensino, "canibalismo" caracterizado pela oferta de cursos similares dentro da mesma região de abrangência e a sazonalidade da demanda, são alguns dos motivos que interferem no marketing educacional de uma Instituição de Ensino Superior Privada.
Deixar de diferenciar-se e de buscar práticas de marketing que contribuam para a captação e, principalmente, para a manutenção dos alunos, pode ser a diferença entre sair do mercado ou tornar-se referência em educação.

\section{Marketing Educacional, Conceitos e Definições}

\subsection{Conceito Geral de Marketing}

Segundo Casas (2006:9), marketing é o processo de planejamento e execução da concepção, preço, promoção e distribuição de idéias, bens e serviços, organizações e eventos para criar trocas que venham a satisfazer objetivos individuais e organizacionais.

Sendo assim, no contexto educacional, podemos inferir que o marketing envolve ações que delineiam programas de ofertas da instituição para atender às necessidades e aos desejos do mercado-alvo, utilizando o composto mercadológico para informar, motivar e atender a esses mercados.

O composto mercadológico compreende os 4 Ps do marketing que são o produto, o preço, a praça e a promoção. O produto compreende a variedade, design, qualidade, nome de marca, embalagem, tamanhos, garantias e serviços. O preço compreende o preço nominal, descontos, concessões, prazos para pagamento e condições de crédito e é o único "P" gerador de receita. A praça, no Brasil, intitulada canais de distribuição, compreende a cobertura, pontos-devenda, estoque e transporte. Por último, temos a promoção que envolve toda estratégia de comunicação de uma empresa, através da utilização de promoção de vendas, propaganda, força de vendas, relações públicas e marketing direto.

No serviço educacional, o composto mercadológico (4Ps), precisa estar sincronizado para garantir a qualidade do serviço. Não adianta investir em marketing de relacionamento se algum dos Ps não atender aos desejos e necessidades do aluno, ou seja, não adianta ter um preço acima do mercado e uma praça (campus universitário) de difícil acesso para o perfil dos candidatos da instituição.

No entanto, é preciso entender Marketing Educacional de forma diferente do Marketing de Bens, no que se refere ao tratamento do composto 
mercadológico. É imprescindível para o gestor de bens como o de serviços compreenderem seu mercado e o processo de motivação de compra de seus clientes.

Nesse sentido, Casas (2002: 27), confirma nosso posicionamento quando relata que "não há diferenças significativas nas formas de entender e abordar o mercado, mas na elaboração do composto mercadológico".

Portanto, o Marketing Educacional compreende a oferta de serviços intangíveis e que são avaliados a partir da percepção de qualidade e criação de valor para o cliente. Nesse sentido, a marca, a embalagem, que correspondem à forma dos funcionários se vestirem, à mobília, disposição do layout nos escritórios e ao preparo de propostas, entre outras, as evidências físicas e, principalmente, as pessoas, são os fatores determinantes da escolha de uma Instituição de Ensino Superior Privada em detrimento de outra.

É através das pessoas que acontece o contato íntimo e permanente com os alunos atuais e futuros, expressado na forma de relacionamento. Portanto, além do preço, produto, distribuição e comunicação, devemos considerar a influência das pessoas na oferta de serviços.

\section{As Pessoas e o Marketing Educacional}

As pessoas ajudam a formar a imagem da empresa, pois sendo o serviço educacional um bem intangível, estas se tornam a referência e o sinal de credibilidade que os clientes procuram no momento da finalização de uma compra. Atendentes uniformizadas, atenciosas, conhecedoras dos procedimentos da instituição de ensino e um corpo docente qualificado, constituem o diferencial competitivo que levará o cliente a optar por uma IESP em vez de outra.

As instalações das Instituições de Ensino Superior Privadas, como bibliotecas, salas de aula confortáveis, estacionamento, segurança, áreas de conveniência são commodities, ou seja, são entendidas pelo cliente como requisitos básicos de uma instituição de ensino.

Diante de tudo isso, a construção do relacionamento estável e duradouro com todos os alunos será o diferencial diante do desafio imposto pelo ambiente competitivo onde as instituições estão inseridas.

E, seja qual for a velocidade destas mudan- ças, o relacionamento será o denominador comum para obtenção de vantagem competitiva sustentável. Nesse contexto, surge o Marketing de Relacionamento que, segundo Casas (2006: 26), consiste na relação com o consumidor, no tocante à comunicação e à coleta de informações para mensurar e acompanhar a satisfação do cliente.

Para desenvolver um bom marketing de relacionamento é necessário que as Instituições de Ensino Superior Privadas invistam em tecnologia da informação (TI).

A Tecnologia da Informação (TI) deve ser entendida como a coleta, processamento, armazenamento, apresentação e transmissão da informação em todas as suas formas. Inclui computadores, telecomunicações, redes de informações, internet, superinfovias, on-line databases, softwares, bem como fax, telefonia móvel, televisão à cabo e outras formas de comunicação pessoal e de massa (BRETZKE, 2000: 11).

As Instituições de Ensino Superior Privadas, cada vez mais, investem em atividades e criam estratégias para captação de novos alunos; participam de feiras e eventos educacionais, realizam visitas orientadas e abrem suas portas para que alunos do ensino médio conheçam as instalações de seus campi e vivenciem o ambiente universitário numa tentativa de influenciar a escolha do futuro universitário.

Em decorrência destas atividades, vários cadastros são realizados. Informações preciosas que devem ser gerenciadas através das ferramentas de tecnologia da informação. Essas informações sobre clientes atuais e futuros devem estar cadastradas em um Data Base Marketing (Banco de Dados de Marketing) e posteriormente serem utilizadas numa estratégia de CRM que consiste no Gerenciamento do Relacionamento com o Cliente.

CRM, Customer Relationship Management ou Gerenciamento do Relacionamento com Cliente, é a integração entre o Marketing e a Tecnologia da Informação. Seu objetivo é prover as empresas de meios mais eficazes e integrados para atender, reconhecer e cuidar do cliente, 
em tempo real e transformar esses dados em informações que, disseminadas pela organização, permitam que o cliente seja “conhecido" e cuidado por todos e não só pelas operadoras de Call Center ou pelos vendedores (BRETZKE, 2000: 29).

As instituições de ensino superior privadas utilizam, em seu composto mercadológico, estratégias de comunicação para informar ao mercado-alvo os cursos e serviços que têm a oferecer. Para atingir este propósito, várias ferramentas do composto de comunicação podem ser utilizadas, como propaganda, relações públicas e publicidade, venda pessoal, marketing direto, promoção de vendas e/ou marketing digital. Segundo Costa e Crescitelli (2003: 58), embora todas as ferramentas de comunicação tenham objetivos comuns, elas possuem, entre si, características diferenciadas que permitem sua utilização em situações distintas, para solucionar problemas diferentes, a critério das decisões da empresa.

Ao fazer o planejamento de comunicação, devemos considerar o estágio do relacionamento com o atual e futuro aluno e os eventos que podem disparar uma ação de mala direta ou telemarketing ativo, que seriam, nesse caso, as ferramentas ideais para atingir este objetivo específico.

Dessa forma, as instituições de ensino estabelecem seu ponto de contato com o mercado alvo e apresentam seus diferenciais de qualidade. Mas é nos chamados "momentos da verdade", quando os prospects tornarem-se efetivamente alunos da instituição, que acontecerá a comparação entre o que foi prometido e o que realmente está sendo ofertado após a compra dos serviços. Nesse momento, o Marketing de Relacionamento assume papel de fundamental importância, pois ao permitir que os desejos e necessidades do aluno sejam conhecidos por todos na instituição, a percepção de qualidade por parte do aluno tende a ser de satisfação ou até mesmo de encantamento pelo serviço contratado.

\section{Conclusão}

O valor estratégico do Marketing de Relacionamento, através da implantação de um CRM, é percebido pelo aumento do conhecimento dos desejos, necessidades e expectativas dos alunos, pelo aumento da retenção e fidelidade dos mesmos, pela experiência de marca positiva e pela diferenciação dos serviços que correspondem ou superam o que o aluno espera, além de aperfeiçoar o processo decisório e estabelecer um relacionamento diferenciado.

Dessa forma, nosso aluno torna-se o principal multiplicador da qualidade dos cursos e serviços oferecidos pela instituição de ensino superior privada.

Portanto, oferecer boa infra-estrutura, com laboratórios especializados, corpo docente qualificado, bibliotecas informatizadas e conveniência são pré-requisitos que somente terão valor se funcionários administrativos e professores estiverem comprometidos com a instituição e considerarem que o relacionamento é o ponto-chave para a manutenção dos alunos. 


\section{Referências}

1 - BRETZKE, Miriam. Marketing de relacionamento e competição em tempo real com CRM. São Paulo: Atlas, 2000.

2 - LAS CASAS, Alexandre Luzzi. Administração de marketing: conceitos, planejamento e aplicações à realidade brasileira. São Paulo: Atlas, 2006.

$3-$ Marketing de Serviços. 2. ed. São Paulo: Atlas, 2002.

4 - COSTA, Antonio R.; CRESCITELLI, Edson. Marketing promocional para mercados competitivos: Planejamento, Implementação e Controle. São Paulo: Atlas, 2003.

5 - EDUDATA BRASIL. Sistema de Estatísticas Educacionais, disponível em : www.edudatabrasil.inep.gov.br

6 - GARCIA, Maurício (org.). Gestão profissional em instituições privadas de ensino superior: um guia de sobrevivência para mantenedores, acionistas, reitores, pró-reitores, diretores, coordenadores, gerentes e outros gestores institucionais. Espírito Santo: Hoper, 2006.

Informações bibliográficas:

Conforme a NBR 6023:2002 da Associação Brasileira de Normas Técnicas (ABNT), este texto científico publicado em periódico eletrônico deve ser citado da seguinte forma:

MARTINS, D. C. L.; OLIVEIRA, I. R. S., MARTINS, S. J.. A Importância do Marketing de Relacionamento na Gestão das Instituições de Ensino Superior Privadas. Cadernos UniFOA, Volta Redonda, ano II, n. 4, agosto. 2007. Disponível em: <http://www.unifoa.edu.br/pesquisa/caderno/edicao/04/35.pdf> 